\title{
Exploring the Role of Communication in Inclusive Education for Children with Learning Disabilities
}

\author{
Yi Chen* \\ School of Foreign Languages \\ Guangdong University of Science \& Technology \\ Dongguan, China
}

\begin{abstract}
Teacher-parent or teacher-student communication is necessary for dealing with teaching issues. As for children with learning disabilities, it is even more self-evident. While the teacher-parent communication can promote parental involvement in education, which is being advocated nowadays, teacher-student communication can help promote inclusive education. In most cases, LD children have troubles in school performance, which has attracted educators' or parents' (caregivers) great attention. The paper is to study how to create an inclusive classroom environment for LD children through communication. It analyzes the importance of communication in building up an inclusive classroom and then the conclusion is drawn out that both the positive teacher-parent and teacherstudent communication can greatly advance the development of inclusive education and benefit the learning results/efficiency of LD children.
\end{abstract}

Keywords-LD children; teacher-parent communication; teacher-student communication; inclusive education

\section{INTRODUCTION}

Inclusive education regards all children as a whole and they are treated equally without distinction, which is undoubtedly a great blessing for children with learning disabilities (LD children). This group of children with special needs is not physically handicapped like deaf or blind children. They only have unbalanced development in some cognitive aspects such as memory. Therefore, inclusive teaching for LD children is of great significance. This paper is going to explore the significance of communication in inclusive education for LD children.

\section{LD CHILDREN’S INCLUSIVE EDUCATION}

\section{A. The Role of Parents in LD Children's Inclusive Education}

Inclusive classroom requires that the wide differences in students' characteristics and needs must be taken into account and education discrimination and inequity must be eliminated, which is a brand-new educational concept [4]. LD children, as a significant, special and huge group, are more concerned by us in an inclusive classroom. Research has shown that the number of LD children accounts for $4 \% \sim 6 \%$ of the total number of school-age children [5]. In my past experience as a primary math teacher for LD children (age: 8-9 years old), I deeply realize how important the positive communication with both the children and the parents (or carers) is. The involvement of parents in education is also crucial to the success of the inclusive classroom. Research shows that parents' participation in teaching can actively improve children's enthusiasm for learning and has a strong positive effect on the inclusive teaching results [7]. Therefore, teachers should maintain regular contact with parents of $\mathrm{LD}$ children in order to better promote the children's school performance.

LD children have their own particularity, characteristics and needs. Parents are their closest people in the world and relatively have a deeper understanding of them. The goal of inclusive education is to achieve personalized teaching and make a unique goal for each student's growth and learning plan [2]. The smooth development of inclusive classroom requires teachers to have a correct orientation for each student. Only through communication can teachers build beneficial cooperation with carers and then deepen the understanding of LD children. Thus, an inclusive classroom can be managed in an effective manner. Once such cooperation is established, LD children can benefit a lot from it. Under the cooperative guidance of parents and teachers, LD children can re-examine themselves, identify their defects, and then make up for them by themselves [7]. Not being good at the moment does not mean not being good in the future. Once being the LD children, Einstein, Newton and Lee Kuan Yew are all successful persons. Then, teachers and parents can cooperate to encourage LD children to actively find out their own interests and tap into their potential. Next, research shows that this kind of cooperation is conducive to regain LD children's selfconfidence [5]. What's more, the encouragement and understanding from both the parents and teachers are beneficial for LD children's learning harmoniously in the inclusive classroom and exchanging their ideas with parents, teachers and classmates.

\section{B. The Significance of Communication in LD Children's Inclusive Education}

How should teachers effectively communicate with LD children and manage them to promote appropriate classroom behaviors? How should teachers actively collaborate with their parents through communication to create an effective inclusive classroom? What is the role and significance of communication and cooperation between teachers and parents towards an effective inclusive education for LD children? All these questions focus on one word, "communication". The healthy growth of LD children requires intense cooperation between schools and families. Thus, it is crucial to create a fine school- 
family relationship. Research has shown that effective communication between teachers and parents can positively promote the parents to participate in their children's learning process, which can improve children's enthusiasm for life and study and also strengthen the parent-child relationship [7]. Thus, it can be concluded that appropriate communication can promote the formation of a good school-family relationship and is beneficiary for the inclusive education. Moreover, teacherstudent communication can also benefit the establishment of a fine relation between the two sides. Besides exploring the significance of teacher-student communication, this paper cares about most is the role of communication and cooperation between teachers and parents towards an effective inclusive education for LD children. Dewey once points out that shared interests between members can result in communication in a community [3]. It is no doubt that the shared interests between parents and teachers exist. For parental involvement is indispensable in inclusive education, teacher-parent communication is even more crucial.

\section{HOW TO STRENGTHEN COMMUNICATION IN PROVIDING INCLUSIVE EDUCATION FOR LD CHILDREN}

Classroom teaching is both a major component of school education and a dynamic interpersonal activity composed of teachers, students, and parents. An inclusive classroom is the most basic and main link in inclusive education. So building up an ideal inclusive classroom is crucial for LD children. Under the guidance of the concept of inclusion, teachers implement inclusive teaching and need to illustrate inclusive education with their hearts. Without discrimination against LD children, teachers should have noble morality and understand and care about them with a loving heart. Effective communication among teachers, students and parents is crucial to the education of LD children [5]. Moreover, inclusive education should provide a platform of communication for them. As for LD children, they are much more often neglected in the classroom and always become listeners in the teaching process. Therefore, teachers should actively communicate with LD students and formulate targeted teaching strategies to let them learn and for in an inclusive classroom.

It has been proved that parents' involvement in education can positively influence children's academic success. Recently, the initiatives of "Parents as Teachers" have been launched and studied, which has found the children involved in such initiatives can perform better in the aspects of reading and math [7]. Thus, it can demonstrate that parents' involvement in education can promote children's higher scores in school tests. What's more, it is worth noting that the scores aren't affected by the race, sex, characteristics of students [7]. Then, LD children have the same tendency. The above findings can show the great benefits of parents' involvement in inclusive education. Therefore, as for LD children, teachers have to effectively communicate with their parents to ensure the children's active enthusiasm in the study. Moreover, teachers must also carry out in-time communication with LD children. LD children can participate in the inclusive classroom and have a great influence on the smooth development of inclusive education. As for how to communicate with LD children and their parents, the below strategies to guarantee the efficiency of teacher-parent and teacher-student communication are given.

\section{A. To Respect Parents and Actively Affirm the Influence of Parents on Their Children in the Process of Learning}

It can fully give parents self-confidence in LD children's education and also lay a solid foundation for them to participate in LD children's learning process, which is conducive to the establishment of an inclusive classroom [2]. As we all know, mutual respect is the premise of communication. Although teachers play a leading role in the relationship, the two sides are completely equal in personality. Therefore, teachers must show respect to parents and pay attention to wordings and body language in order to avoid misunderstanding. In this way, teachers and parents of LD children can gradually establish trust, which also means the purpose of interaction has already been half done. It is also very important to affirm the positive role of parents in LD children's learning and growth, which can positively promote parent involvement in the study and push parents to further facilitate themselves with powerful knowledge. Thus, research has demonstrated that parent involvement in children's learning can also greatly improve their own efficacy [1]. Moreover, teachers should elaborate on the particularity of LD children's learning ability and explain to parents the difficulties children may encounter in a detailed manner. For example, LD children usually have difficulty in concentrating and suffer from poor memory. Parents should be tolerant and patient while educating them. Thus, parents can understand their children better, which is a prerequisite for parents to effectively participate in LD children's school education. Recently, research shows that parents' understanding of their children is a decisive factor for them to carry out parent involvement initiatives [1]. It can be seen that teachers can employ their own experience to help parents have a higher level of understanding towards LD children and then encourage them to actively participate in their children's learning. In addition, teachers should also use various successful cases to illustrate the fact that parental involvement has a great positive effect on the school behaviors and test performance of children, which is beneficiary for the establishment of an inclusive classroom. Inclusive education aims to provide personalized training objectives for each student, which requires the participation of both students and their parents.

\section{B. To Create a Good Parent-teacher Relationship through Communication}

It is not enough for LD children to grow up healthily only under the guidance of school or family alone. While teachers cannot observe their students' situation at home, parents also don't know their children's performance in school. This requires a joint effort between the two sides, so inclusive education will be targeted and consistent [6]. It is difficult to realize a fine teacher-parent relation because of parents' various characters and educational ideas. It is a tough task to let them keep pace with the teacher in terms of cultural education. With the purpose of providing an excellent educational environment for LD children, teachers and parents must communicate frequently and cooperate with each other to create a fine parent-teacher relationship. Dewey believes that 
the common interests between communities can result in mutual respect and communication [3]. When the communities are pursuing a common interest, then the forms of cooperation with the aid of communication will come into being. Undoubtedly, there is a common goal between teachers and parents. In terms of children's education, both sides are eager to succeed in cultivating outstanding talents. Therefore, teachers should fully illustrate and enlarge the goal and establish a cooperative relationship with parents. Additionally, in the process of communication, teachers should show their professional abilities to the parents and use rigorous and scientific language to persuade parents to cooperate with them in order to better carry out inclusive education [9]. What's more, teachers should fully demonstrate to LD children's parents the form of inclusive classroom and its goals and benefits for the purpose of improving parents' understanding of inclusive education. Language is a magical tool to connect the whole world, and its words are given meanings for expressing. Teachers should make full use of the words to establish a strong-held connection with parents. Both LD children and their parents all have their own peculiarities and characteristics, and teachers must much more consider matters and make decisions from their perspectives. It is hoped that teachers and parents can work hand-in-hand to go into the hearts of this kind of children and provide them with a much better growth environment. Only in this way can unlimited possibilities be created in the future.

\section{To Improve Teachers' Expression Ways in the Inclusive Classroom}

Teachers should slow down the speed and talk in a gentle manner. In most cases, LD children are more difficult to concentrate and are often distracted in class. So teachers should keep eye contact or verbal communication with LD children through exaggerated body language or attractive stories. Next, teachers should straighten out their roles and act as participants or assistants rather than arbitrary leaders. They should let every student actively express his/her views and learn to connect every teaching link perfectly so that the students have a chance to show themselves to their heart's content. In the inclusive classroom, every student is a participant and teachers should try to encourage LD children to take the initiative to communicate with teachers and their peers and then gradually to be able to express different views. For example, teachers can organize group activities in an inclusive classroom and let them have a group discussion. The comments on the opinions of group members are also required. Various forms of classroom organization can attract LD children, make them fall in love with learning, and gradually step into the right track of study, which is conducive to the smooth development of inclusive classroom [5]. Besides, teachers should also communicate with LD children in a timely manner to grasp students' views or thoughts. In the process of communication with LD children, teachers should have patience and love, go deep into children's hearts, and provide them with suitable teaching services. A good teacher-student relationship plays a vital role in the development of inclusive education. LD children often lack self-confidence and are not active in class. So teachers should communicate with students more after class to teach them how to express opinions. In the face of LD children, teachers should consider matters from their point of view. Teachers can encourage LD children to introduce their good friends and then boast of their friends, which helps pave the way for them to establish healthy interpersonal relationships. Good interpersonal relationships are of great benefit to the healthy growth (study and life) of LD children [8]. After class, teachers can also carry out sports activities (group sports) to make LD children learn how to concentrate on contributing to the group. All these strategies can be realized through active communication, which can be beneficial to creating a meaningful inclusive classroom for LD children.

\section{CONCLUSION}

Based on inclusive education, this paper unveils the role of communication in carrying out the learning process for LD children. Both the teacher-parent and teacher-student communication are equally crucial. While a fine teacher-parent communication can greatly promote not only the forming of a beneficial school-family relationship but also the parental involvement in inclusive education, a good teacher-student communication can be beneficial to creating an ideal inclusive classroom. In an inclusive classroom, LD children must be taken seriously. Moreover, the communication among three parts, that is, the school, teachers and parents, is worthy of being further studied.

\section{ACKNOWLEDGMENT}

The publishing of this paper benefits from the help of many people. While writing, I have confronted with problems. However, my helpful teachers, friends and family members have encouraged me a lot. Therefore, I would like to express my sincere thanks to everyone!

\section{REFERENCES}

[1] B. Whitburn, "The dissection of paraprofessional support in inclusive education: 'You're in mainstream with a Chaperone," Australasian Journal of Special Education, vol. 37, No. 02, pp. 147-161, 2013.

[2] C. Evans and S.L. Weiss, "Teachers working together: How to communicate, collaborate, and facilitate positive behavior in inclusive classrooms," The Journal of the International Association of Special Education, vol. 15, No. 02, pp. 142-146, 2014.

[3] J. Dewey, Democracy and Education: An Introduction to the Philosophy of Education. The Macmillan Company, New York, 2009.

[4] J.R. Ashton, "Beneath the veneer: Marginalization and exclusion in an inclusive co-teaching context,” International Journal of Whole Schooling, vol. 10, No. 01, pp. 43-62, 2014

[5] L.J. Elizabeth, D.S. Kristine, D. Julie and J.R. Mitzi, "Collaborative relationships for general education teachers working with students with disabilities,” Journal of Instructional Psychology, vol. 39, No. 02, pp. 112-118, 2013.

[6] M. Arthur, C. Gordon, and N. Butterfield, Classroom Management: Creating Positive Learning Environments. Thomson, India, 2003.

[7] M. Falkmer, K. Anderson, A. Joosten and T. Falkmer, "Parents" perspectives on inclusive schools for children with autism spectrum conditions," International Journal of Disability, Development and Education, vol. 62, No. 01, pp. 01-23, 2015.

[8] P. Denton, The Power of Our Words: Teacher Language that Helps Children Learn. Center for Responsive Schools, Inc, 2013.

[9] R.S. Sandra and L.S. Dana, "Teachers' investments in and orientations toward parent involvement in education," Urban Education, vol. 44, No. 01, pp. 59-87, 2009. 